\title{
CLINICAL MANIFESTATIONS OF HYPOKALEMIA
}

\author{
Rehana Majeed, Hatif A. Shamsi and Uzma DM Rajar
}

\begin{abstract}
OBJECTIVE: To observe the clinical manifestations of hypokalemia resulting from acute watery diarrhoea.

DESIGN: A descriptive study.

SETTING: Paediatrics department, Isra University Hospital Hyderabad, Sindh from April 2004 to April 2005.

PATIENTS AND METHODS: Children less than 5 years of age with acute watery diarrhoea and vomiting who were found to have hypokalemia were included in this study. Children with chronic diarrhoea (more than 14 days duration) or hypokalemia of any other cause such as Bartter's syndrome etc. were excluded. Children with paralytic ileus due to other causes such as anti-diarrhoeal drugs etc. were also excluded. Serum potassium levels were checked at Isra University research laboratory by the standard ion selective electrode method. Hypokalemia was defined as serum potassium level of less than $3.5 \mathrm{mEq} / \mathrm{l}$. The clinical presentations of children with hypokalemia were recorded and statistically analysed.

RESULTS: During study period, 350 children with acute watery diarrhoea were admitted. Of these, 130 (37.14 \%) were hypokalemic and were included in this study, whereas 220 (62.85\%) children were normokalemic (normal serum potassium level) and therefore were excluded from study. Abdominal distention was the commonest manifestation in $110(84.61 \%)$ children followed by head flop in $90(69.23 \%)$ cases, diminished bowel sounds in 55(42.30\%), paralytic ileus in 30 (23.07\%), inability to sit, stand or walk in $45(34.61 \%)$ and aphonia or dysphonia in $15(11.53 \%)$ children. Five children (3.84\%) with hypokalemia had no clinical manifestation. Examination revealed weakness of limbs in 35 children, out of which 30 children had quadriparesis and 5 had paraparesis.

CONCLUSION: Hypokalemia is an important electrolyte disturbance with acute diarrhoea. It may have serious clinical manifestations like abdominal distention, paralytic ileus, and can even lead to cardiac arrhythmias and arrest. Although, it can have fatal morbidities, timely intervention yields encouraging results.
\end{abstract}

KEY WORDS: Diarrhoea. Hypokalemia. Abdominal distension.

\section{INTRODUCTION}

Diarrhoea is a leading cause of illness and death among children in developing countries, where an estimated 1.3 thousand million episodes and 4 million deaths occur each year in under-five children. An average of 3.3 episodes each year per child occur worldwide, but in certain areas this average exceeds nine episodes each year. In these areas, young children may spend more than $15 \%$ of their days with diarrhoea. About $80 \%$ of deaths due to diarrhoea occur in the first two years of life. The main cause of death from acute diarrhoea is dehydration, which results from the loss of fluid and electrolytes in diarrhoeal stools. ${ }^{1}$ Diarrhoea is an intestinal disorder characterized by abnormal fluidity and increased frequency of faecal evacuation, generally the result of increased motility in the intestine. ${ }^{2}$ Hypokalemia is one of the manifestations of diarrhoea and diarrhoea is one of the most common causes of acute potassium depletion from the body. Other causes include diabetic keto-acidosis, severe gastrointestinal losses from vomiting, dialysis and diuretic therapy. ${ }^{2}$ Serum potassium $\left(\mathrm{K}^{+}\right)$concentration in human beings is maintained by a balance between intake, excretion and distribution of potassium between the intra cellular and extracellular spaces. Potassium is present in most of the foods in varying amount. The average daily $\mathrm{K}^{+}$intake in diet is about 70 milli equivalents under normal conditions. Excretion equals intake, with approximately $90 \%$ of $\mathrm{K}^{+}$excreted in the urine and vast majority of the remainder in the stool. ${ }^{3}$ Approximately $98 \%$ of the $\mathrm{K}^{+}$in body is present in the intracellular space. Intracellular $\mathrm{K}^{+}$averages about $120 \quad 140 \mathrm{mEq} / \mathrm{L}$, largely as a result of active $\mathrm{K}^{+}$uptake by $\mathrm{Na}^{+} \mathrm{K}^{+}$ATP-ase pump. Consequently, small changes in the distribution of $\mathrm{K}^{+}$between the intra and extra cellular fluid spaces 
result in proportionally large change in extracellular $\mathrm{K}^{+}$ concentration. Therefore, even small losses of potassium from the body may result in hypokalemia. The reference range for serum potassium level is 3.5-5 $\mathrm{mEq} / \mathrm{L}$, with total body potassium stores of approximately $50 \mathrm{mEq} / \mathrm{kg}$ (i.e. approximately $3500 \mathrm{mEq}$ in a 70-kg person). Although, the mortality is reported as rare, short-term morbidity is commonly present in children with hypokalemia. This may manifest as gastrointestinal hypo-motility or ileus, cardiac dysrhythmia, QT prolongation, appearance of $U$ wave that mimic atrial flutter, $T$ wave flattening or ST segment depression and muscle weakness or cramping. ${ }^{4-6}$

The aim of this study was to observe clinical manifestations of hypokalemia in our set up.

\section{PATIENTS AND METHODS}

This descriptive study was carried out in paediatric unit of Isra University Hospital Hyderabad, Sindh from April 2004 to April 2005. During study period, a total of 350 children were admitted with acute watery diarrhoea of less than 14 days of duration. The age of these subjects ranged from 2 months to 5 years. Serum potassium was estimated in all these children with ion selective electrode method. Hypokalemia was defined as serum $\mathrm{K}^{+}$of less than $3.5 \mathrm{mEq} / \mathrm{L} .^{7}$ It was graded as mild (serum $\mathrm{K}^{+}$level of $33.5 \mathrm{mEq} / \mathrm{L}$ ), moderate (serum $\mathrm{K}^{+}$level of $23 \mathrm{mEq} / \mathrm{L}$ ) and severe (serum $\mathrm{K}^{+}$level of less than $2 \mathrm{mEq} / \mathrm{L}$ ). ${ }^{8}$ The clinical manifestations observed in this study included neck flop (A child unable to hold neck, who had head control previously), abdominal distention (fullness of abdomen in which bowel sounds are audible normally or may possibly faster), paralysis of limbs, diminished bowel sounds ( 0 or 1 per minute), ability of child to sit, stand or walk noted (in those who previously done so) and paralytic ileus (hypokalemia with signs of ileus). Relevant investigations like $X$ ray abdomen, ECG, stool virology and nerve conduction were also carried out in selected cases. Children with chronic diarrhoea (more than 14 days duration) or children with hypokalemia of any other cause like periodic paralysis, Bartter's syndrome and children with paralytic ileus due to anti-diarrhoeal drugs were excluded.

\section{RESULTS}

Total 350 cases with diarrhoea and vomiting were admitted during study period. Out of these, 130 were hypokalemic and fulfilled the inclusion criteria. Eightyone children (62.30\%) were between 2 months to 2 years of age and 49(37.69\%) were between 2 to 5 years of age. Two hundred and twenty (62.85\%) were under 2 years age and 130 (37.14\%) were between 2

5 years of age. Hypokalemia was found in 130 (37.14\%) children whereas $62.85 \%$ children were normokalemic (serum potassium level normal). Eightytwo cases $(63 \%)$ were moderately hypokalemic, whereas $36(27.69 \%)$ and $12(9 \%)$ cases respectively were having severe and mild hypokalemia. Abdominal distention was the commonest manifestation, found in $110(84.61 \%)$ children followed by head flop in 90 (69.23\%), diminished bowel sounds in 55 (42.30\%) and paralytic ileus in $30(23.07 \%)$ cases (Table I). Five children (3.84\%) with hypokalemia had no clinical manifestation. Examination revealed weakness of limbs in 35 children; 30 children with quadriparesis and 5 had paraparesis. Neurological deficits like quadriparesis and parapersis were commonly seen in subjects with severe hypokalemia while abdominal distention and head leg with moderate hypokalemia. Cardiac arrhythmias and respiratory muscle paralysis were not noticed in this study.

TABLE I:

\section{FREQUENCY OF CLINICAL MANIFESTATIONS OF HYPOKALEMIA}

\begin{tabular}{|l|c|}
\hline \multicolumn{1}{|c|}{ Manifestation } & Number of Cases (\%) \\
\hline Abdominal distention & $110(84.61)$ \\
\hline Neck flop & $90(69.23)$ \\
\hline Diminished bowel sounds & $55(42.30)$ \\
\hline Weakness of limbs & $35(26.92)$ \\
\hline Inability to sit, stand or walk & $45(34.61)$ \\
\hline Paralytic ileus & $30(23.07)$ \\
\hline Dysphonia or aphonia & $15(11.53)$ \\
\hline No clinical manifestation & $05(3.84)$ \\
\hline
\end{tabular}

\section{DISCUSSION}

Gastrointestinal infections tend to be more common in infants and younger children. Younger children with emesis or diarrhoea are at increased risk of hypokalemia, as depletion of volume of fluid and electrolytes from gastrointestinal loss is relatively higher than that in older children and adults. ${ }^{9,10}$ Hypokalemia is commonly noted in our part of world with acute diarrohea. In this study, $37 \%$ of children with acute diar- 
rhoea were found to be hypokalemic. Sarfraz M in 1989 from Rawalpindi, Pakistan has reported hypokalemia in $25 \%$ of cases, ${ }^{11}$ little lesser than present study. However, Majeed R from Hyderabad, Pakistan in 2001 had found $30 \%$ of children having hypokalemia with acute watery diarrohea comparable with this study. ${ }^{12}$ Gomber S, et al from India has reported neck flop as the commonest presenting clinical manifestation followed by abdominal distension. ${ }^{13}$ In this study, neck flop was second most common presentation. Meanwhile, Chhabra A, et al from India in 1995 found neck flop as the commonest (100\%) clinical manifestation followed by diminished bowel sounds (82.6\%), trunchal weakness (52\%), weakness of limbs $(52 \%)$, lethargy (43\%) and two cases of flaccid paralysis of both lower limbs. ${ }^{14}$ This is in contrast to our study and comparable to Gomber S's study which had smaller sample size of only 38 patients. Paralytic ileus was found in 30(23.07\%) children in our study population whereas it was reported significantly higher by Murtaza A, et al. ${ }^{15}$ They have reported that 35\% infants with acute diarrhoea showed abdominal distention and $12 \%$ had full clinical picture of paralytic ileus in $1989 .{ }^{15}$ Potassium deficiency alters functions of several organs and most prominently affects the cardiovascular and neurological systems, muscles and kidneys. ${ }^{2}$ These effects ultimately determine the morbidity and mortality. It can also result in several muscle related complications. Hypokalemia hyperpolarizes the skeletal muscle cells impairing their ability to develop the depolarization, which is necessary for muscle contraction. It can also reduce blood flow to skeletal muscles. The combination of these effects may lead to muscle weakness, easy fatigability, cramping and myalgias. Paralysis is uncommon but can occur in cases of profound $\mathrm{K}+$ deficiency. $^{2}$ Ortuno, et al has reported hypokalemic induced paraplegia secondary to acute diarrhoea in their case series ${ }^{16}$ Kinik ST, et al has also reported a case of hypokalemic paralysis associated with acute gastroenteritis. ${ }^{17}$ In this study, children's examination revealed weakness of limbs in 35 cases, majority with quadriparesis but the complete paralysis was not observed in any children. However, Uysal G, et al in 2000 from Turkey has identified hypokalemia as a fatal risk factor among hospitalized children. ${ }^{18}$

\section{CONCLUSION}

Hypokalemia is one of the commonest electrolyte disturbances with acute diarrhoea. It has diverse as well as serious clinical manifestations like abdominal distention, paralytic ileus, dysphonia or aphonia or inability to sit, walk or stand and can even lead to cardiac arrhythmias and arrest. Although, it can have fatal consequences, timely intervention yields encouraging results.

\section{REFERENCES}

1. World Health Organisation. Teaching of medical students about diarrhoeal diseases. Available at http://www.who.int/child-adolescent. Accessed July 2006.

2. Rehydration project. World Health Organization. Geneva: 1996-2000.

3. Greenbaun LA. Pathophysiology of body fluids and fluid therapy. In: Nelson's textbook of pediatrics. 17th Edition. Behrman RE, Kliegman RM. Philadelphia, WB Saunders. 2004; Pp. 202-8.

4. Knochel JP. Neuromuscular manifestation of electroyte disorders. Am J Med. 1982; 72: 52135.

5. Helfant RH. Hypokalemia and arrhythmias. Am J Med. 1986; 80:13-22.

6. Cannon P. Recognizing and treating cardiac emergencies due to potassium balance. J Cardiovasc Med. 1983; 4: 467-76.

7. Mandal AK. Hypokalemia and hyperkalemia. Med Clin North Am. 1997;81:611-39.

8. Schwartz WB. Disorders of fluid electrolyte balance. In: Cecil's textbook of medicine. $15^{\text {th }}$ Edition. Besson PB, Mcdermott W, Wyngarden JB (edi). Philidelphia, WB Saunders. 1979: P.1957.

9. Rose BD. Introduction to disorders of potassium balance. In: Clinical physiology of electrolyte disorders. 1989. Pp. 715-56.

10. Stephenson T, Rutter N. Sodium and potassium. In: Campbell AGM, Mcintosh NE. Forfar and Arneil textbook of paediatrics. 5th Edition. New York, Churchil livingstone. 1998.

11. Sarfraz M. Aetiology of acute gastroenteritis. Dissertation. Military Hospital Rawalpindi, Pakistan. 1989.

12. Majeed R. Serum sodium in acute diarrhoea. Dissertation. Liaquat Medical College Hospital Hyderabad, Pakistan. 2001.

13. Gomber S, Mahajan V. Clinico-biochemical spectrum of hypokalemia. Indian Pediatr. 1999;36:1144-46.

14. Chhabra A, Patwari AK, Aneja S, Chandra J, Anand VK, Ahluwalia TP. Neuromuscular manifesta- 
tions of diarrhoea related hypokalemia. Indian Pediatr. 1995;32:409-15.

15. Murtaza A, Khan SR, Butt KS, Finkley A. Paralytic ileus, a serious complication in acute diarrhoeal disease among infants in developing countries. Acta Pediatr Scand.1989; 78:701-5.

16. Ortuno Anderiz F, Cabello Clotet N, de Diego Gamarra R, Salaverria Garzon I, Vazquez Rizaldos S. Hypokalemia induced paraplegia secondary to acute diarrhoea. An Med Interna. 2002; 19:76-8. Spanish.

17. Kinik ST, Secmeer G, Kanra G, Ceyhan M, Ecevit Z, Halit K, et al. Hypokalemic paralysis in association with acute gastroenteritis; a report of a sporadic case. Acta Paediatr Jpn. 1998; 40:143-5.

18. Uysal G, Sokmen A, Vidinlisan S. Clinical risk factors for fatal diarrhoea in hospitalized children. Indian J Pediatr. 2000;67:329-33.

AUTHOR AFFILIATION:

Dr. Rehana Majeed (Corresponding Author)

Assistant Professor of Paediatrics

Isra University PO Box\# 313, Hala Road, Hyderabad - Sindh.

E-mail:drrehanamajeed@yahoo.com

Dr. Hatif A. Shamsi

Assistant Professor of Paediatrics

Isra University Hyderabad - Sindh.

Dr. Uzma DM Rajar

Assistant Professor of Dermatology

Isra University Hyderabad - Sindh. 